\title{
Rejection of organic micro-pollutants from water by a tubular, hydrophilic pervaporative membrane designed for irrigation applications
}

\author{
May N. Sule, Michael. R. Templeton and Tom Bond* \\ Department of Civil and Environmental Engineering, Imperial College London SW7 2AZ, \\ $U K$ \\ *Corresponding author. Email: t.bond@,imperial.ac.uk. Telephone: +44(0)207 5946018 \\ Email addresses for other authors: maysule@yahoo.com; m.templeton@imperial.ac.uk
}




\begin{abstract}
The links between chemical properties, including those relating to molecular size, solubility, hydrophobicity and vapour pressure, and rejection of model aromatic micro-pollutants by a tubular, hydrophilic polymer pervaporation membrane designed for irrigation applications was investigated. Open air experiments were conducted at room temperature for individual solutions of fluorene, naphthalene, phenol, 1,2-dichlorobenzene, 1,2-diethylbenzene and 2phenoxyethanol. Percentage rejection generally increased with increased molecular size for the model micro-pollutants $(47 \%-86 \%)$. Molecular weight and $\log \mathrm{K}_{\mathrm{ow}}$ had the strongest positive relationships with rejection, as demonstrated by respective correlation coefficients of $\mathrm{r}=0.898$ and 0.824 . Rejection was also strongly negatively correlated with aqueous solubility and H-bond $\delta$. However, properties which relate to vapour phase concentrations of the micro-pollutants were not well correlated with rejection. Thus, physicochemical separation processes, rather than vapour pressure, drives removal of aromatic contaminants by the investigated pervaporation tube. This expanded knowledge could be utilised in considering practical applications of pervaporative irrigation systems for treating organiccontaminated waters such as oilfield produced waters.
\end{abstract}

Keywords: Pervaporation, membrane, irrigation, micro-pollutants, hydrophilic.

\title{
Introduction
}

Water scarcity is driving the need for technologies that will allow the treatment of polluted source waters for human activities, such as drinking water production and irrigation. For example, in some parts of the world, it may be desirable for the waters resulting from oil/gas production to be put to such beneficial re-use applications. However, such waters are typically highly saline and often contain at least trace amounts of a range of environmentally 
harmful organic contaminants. In oilfield-produced water these include aromatic compounds benzene, toluene, ethylbenzene and xylenes, known collectively as 'BTEX', as well as polynuclear aromatic hydrocarbons (PAHs), phenols and other compounds [1]. While a variety of technologies have been previously investigated for BTEX removal, including membrane bioreactors [2], a biotrickling filter [3] and a variety of adsorbents [4], low energy methods for selective removal of such micro-pollutants from water would be advantageous.

In this study, the removal of representative aromatic micro-pollutants using a hydrophilic tubular pervaporative membrane designed for irrigation applications was investigated. Pervaporation (i.e. permeation and evaporation) is a separation process in which a multicomponent liquid is passed across a non-porous, selectively permeable membrane that preferentially transports one or more of the components. The three key steps involved in the process are dissolution, diffusion and evaporation $[5,6]$. This approach can potentially be used as an irrigation technology is for a tube made of a pervaporative polymer to be filled with water and buried in soils at approximately the root level of the target crops, with water pervaporating across the membrane wall and contaminants held within the tube (periodic flushing would be required to prevent accumulation of the contaminants within the tube).

The removal of salts using these pervaporation tubes has been previously demonstrated [7]. However, there is very limited information available about how effective this technology is for rejecting pollutants found in oilfield-produced water. Hence, the aim of this study was to investigate the rejection of organic micro-pollutants by the tubular pervaporative polymer membrane. Fluorene, naphthalene, phenol, 1,2-diethylbenzene, 2-phenoxyethanol, and 1,2dichlorobenzene were used as model aromatic micro-pollutants.

\section{Materials and methods}


The polymer membrane that was used in this research was a non-porous, hydrophilic membrane composed of a thermoplastic block copolymer of the polyester family synthesised by Du Pont de Nemours International SA, Geneva and extruded into a corrugated tubular form, with inner corrugated diameter of $19 \mathrm{~mm}$, outer corrugated diameter of $23 \mathrm{~mm}$, membrane thickness of $0.75 \mathrm{~mm}$, and ridge width of $7 \mathrm{~mm}$. This corresponds to a linear mass of $90 \mathrm{~g}$ per metre length of tube. Analytical grade 1,2-diethyl benzene, 1,2-dichlorobenzene, 2-phenoxyethanol, phenol, naphthalene, and fluorene were obtained from Sigma-Aldrich, Dorset, UK. Structures and selected properties $[8,9,10]$ for model micro-pollutants are given in Table 1. Molecular weight, molecular volume and kinetic diameter were selected as they are related to molecular size. Various other properties were selected on the basis that they are linked to solubility: the octanol/water partition coefficient $\left(\log \mathrm{K}_{\mathrm{ow}}\right.$, a measure of hydrophobicity), aqueous solubility and H-bond $\delta$. The latter may require some introduction. H-bond $\delta\left(\right.$ or $\delta_{\mathrm{H}}$ ) is the hydrogen bonding interaction contribution (or H-bond cohesion (solubility) parameter) obtained from Hansen's solubility parameters [10]. It has previously been used to quantify hydrogen bonding interactions between polymer molecules and solvents and is therefore relevant to pervaporation applications [10, 11]. Finally, boiling point, Henry's Law constant, and vapour pressure were selected as they are associated with gaseous concentrations of the model micro-pollutants. Vapour pressure values were calculated using the Antoine equation:

$$
\log V P=\mathrm{A}-\frac{\mathrm{B}}{T+C-273.15}
$$

Where $\mathrm{VP}=$ vapour pressure, $\mathrm{T}=$ temperature and $\mathrm{A}, \mathrm{B}$ and $\mathrm{C}$ are compound-specific coefficients (Antoine's A, B and C coefficients).

The strength of linear relationships between removal and physicochemical properties of the organic compounds were evaluated using Pearson product-moment correlation coefficients. 
These can take values between -1 (total negative correlation) and 1 (total positive correlation).

Permeation/diffusion tests were undertaken in the open air to evaluate the rate of water and contaminant transport across the tubular polymer membrane $[12,13]$. For experiments with the model micro-pollutants, each end of a $400 \mathrm{~mm}$ length of the tubular membrane was inserted into a neoprene tube leaving $350 \mathrm{~mm}$ of the PV tubular membrane for pervaporation to occur. Both ends were tightly wound with parafilm to seal all gaps between the PV tube and neoprene tube. The tubes were filled with contaminant solution and then the ends were tightly plugged with rubber bungs and sealed. The two ends of the sealed pipe were each clamped to a retort stand leaving the remainder of the tube suspended (in air) in a temperature-controlled laboratory at $21 \pm 1^{\circ} \mathrm{C}$ (Figure 1). In order to simulate real-life conditions no attempts were made to control humidity. The tubes were unclamped and weighed daily to measure mass change and consequently calculate permeate flux. At the end of an experimental run, the concentration of the contaminant solution in the tube was measured using UV-Vis spectrophotometry (Shimadzu UV-2401 PC). In these experiments, no provision was made to maintain a high vapour pressure gradient across the membrane, unlike in Quinones-Bolanos et al. (2005), to more closely simulate the conditions of a tube buried in soil with no vacuum applied. Rather, in this work, the driving force was the vapour pressure difference between the surrounding ambient environment and that in the solvent filled tube.

\section{-Insert Table 1-}

The permeate flux $\mathrm{J}_{i}$ was quantified as the mass water $\left(\mathrm{M}_{\mathrm{w}}\right)$ permeating through the membrane per unit of time ( $\mathrm{t}$ ) per unit area (A)

$$
\mathrm{J}_{i}=\frac{\mathrm{M}_{w}}{\mathrm{At}}
$$


Rejection of contaminants was calculated in terms of an enrichment factor, the ratio between the concentration of the contaminant in the permeate $\left(C_{\text {perm }}\right)$ to that in the feed $\left(C_{\text {feed }}\right)[14]$,

$\beta=\frac{C_{\text {perm }}}{C_{\text {feed }}}$

In this study the feed concentration and volume was measured directly and the permeate concentration calculated indirectly from measurements made to the feed solution:

$\beta=\frac{\left(C_{i} \times V_{i}\right)-\left(C_{f} \times V_{f}\right)}{C_{f} \times\left(V_{i}-V_{f}-\frac{\Delta M}{\rho_{\text {water }}}\right)}$

Where $C_{i}$ and $C_{f}$ are respectively the initial and final concentration of feed solution, while $V_{i}$ and $\mathrm{V}_{\mathrm{f}}$ are respectively the initial and final volume of feed solution and $\Delta \mathrm{M}$ is the change in membrane mass. Use of this equation is based on the assumption that the amount of contaminant remaining inside the membrane is insignificant. In addition, control experiments were undertaken using non-pervaporative plastic tubes of similar dimensions to the actual pervaporation tubes. These demonstrated no significant change in concentrations of the model contaminants over the experimental timescale studied. It is also worth noting that boiling points of the model contaminants are relatively high at $181-295{ }^{\circ} \mathrm{C}$ (Table 1), so volatilisation into any headspace present was not expected to be important.

Percentage rejection $(\mathrm{R})$ was then calculated as:

$\% R=\left(1-\frac{C_{p}}{C_{f}}\right) \cdot 100$

where $\mathrm{C}_{\mathrm{p}}$ and $\mathrm{C}_{\mathrm{f}}$ are calculated as defined above.

All experiments were undertaken for 7 days in at least triplicate. UV-Vis spectrophotometry was applied to quantify the aromatic micro-pollutants. The quantification wavelengths used 
for the different compounds were $193 \mathrm{~nm}$ for 1,2-diethyl benzene, $254 \mathrm{~nm}$ for naphthalene, fluorene, 2-phenoxyethanol and phenol [15, 16], and $220 \mathrm{~nm}$ for 1,2-dichlorobenzene. The starting concentrations of the micro-pollutants reflects the different aqueous solubilities of the compounds and also typical concentrations in oifield produced waters.

\section{Results}

\section{Effect of organic micro-pollutants on water flux}

The average water flux ranged between $3.7 \times 10^{-2}-3.9 \times 10^{-2} \mathrm{~L}\left(\mathrm{~m}^{-2} \cdot \mathrm{h}^{-1}\right)$ for the micropollutant solutions and $5.5 \times 10^{-2} \mathrm{~L}\left(\mathrm{~m}^{-2} \cdot \mathrm{h}^{-1}\right)$ for pure water (Table 2). The reduction in water flux associated with the organic contaminants can be explained by multiple factors. Reduced water flux and sorption in the presence of inorganic salts, relative to equivalent pure water values, for the same pervaporation membrane as used in this study have been reported previously [7]. This trend can be explained by the addition of solutes to water increasing entropy and also lowering the chemical potential of the solution [18]. These changes will also be reflected in reduced adsorption and vapour pressure, which can be viewed as the escaping tendency of the solute [19] and which will reduce overall flux. Concentration polarisation at the membrane surface may also play a role in the reduced flux [20].

-Insert Figure 1-

-Insert Table 2-

\section{Rejection of organic micro-pollutants}

There was a wide variation in removal efficiency (\% rejection) for the different micropollutants $(47 \%-86 \%)$ (Table 2). Fluorene was best removed (86\%) while phenol was least removed $47 \%$. The difference between the molar volume of water $\left(18 \mathrm{~cm}^{3}\right)$ and of the model micropollutants $\left(89.11-122.85 \mathrm{~cm}^{3}\right)$ favoured the selective permeation of water over the micro-pollutants. Water is both preferentially dissolved and transported over larger molecules 
in hydrophilic membranes due to its smaller molecular size [11]. In addition, Berens [22] found that diffusion coefficient (D) decreases with increasing permeate weight, size (molecular volume) and cross sectional area of the penetrant. Similarly, Shao and Huang [11], reported that the diffusion coefficient of a permeate through a polymer is a strong function of the size and shape of the permeate, and Park et al. [23] reported that the intrinsic diffusion coefficient $\mathrm{D}$ of a solvent in samples decreased with an increase in the average molecular diameter $d_{m}$ of the solute. Diffusion coefficients tend to decrease with increasing contaminant molecular volume because of the higher activation energy required for diffusion through a polymer matrix. When molecular weight and chemical nature are the same, molecules with smaller cross-section diffuse faster $[24,25,26]$.

\section{-Insert Figure 2-}

Hydrogen-bonding interaction has also been proposed as a dominant factor controlling the selectivity toward water in hydrophilic pervaporation process [27]. In this study, an enhanced propensity for hydrogen-bonding influenced the rejection of phenol $(\delta \mathrm{h}=14.9)$ and 2 phenoxyethanol $(\delta \mathrm{h}=14.3)$, as these compounds had the lowest removal of $47 \%$ and $58 \%$ respectively, whereas fluorene, which has the second lowest hydrogen bonding parameter among the seven studied compounds $(\delta \mathrm{h}=1.7)$, was best rejected. The compound with the lowest hydrogen bonding was 1,2 diethylbenzene $(\delta \mathrm{h}=1)$, for which $66 \%$ rejection was observed. This might also be linked to the latter's higher water solubility of $70 \mathrm{mg} / \mathrm{L}$ and initial feed concentration of $68 \mathrm{mg} / \mathrm{L}$, compared to fluorene's water solubility of $1.98 \mathrm{mg} / \mathrm{L}$ and initial feed concentration of $1.75 \mathrm{mg} / \mathrm{L}$.

The rejection of the model micro-pollutants was also affected by the $\log \mathrm{K}_{\mathrm{ow}}$ values (Figure 2). Organic compounds with $\log \mathrm{K}_{\mathrm{ow}}>3$ had a better removal rate than those with $\log \mathrm{K}_{\mathrm{ow}}<2$ Figure 2; Table 1). Sangam and Rowe [24] reported a decrease in diffusion coefficient D of compounds with high $\log \mathrm{K}_{\mathrm{ow}}$ values. The fact that flourene, with the highest molecular 
volume of $188 \mathrm{~cm}^{3}$, was best rejected supports this explanation. Since each of these properties appears to play a role, Pearson product-moment correlations were applied to the data to examine the relative importance of the properties on contaminant rejection and how the properties themselves are interrelated (Table 3).

\section{-Insert Table 3-}

The strongest positive correlation coefficients involving rejection were with molecular weight, $\log \mathrm{K}_{\mathrm{ow}}$ and kinetic diameter: $\mathrm{r}=0.898,0.824$ and 0.696 , respectively (Table 3 ). These three properties were all positively correlated with one another: $r$ values from $0.607-$ 0.964 (Table 3). Thus, rejection increases with both molecular size and hydrophobicity of the model compounds, as might be expected for a hydrophilic membrane. However, since $\log \mathrm{K}_{\mathrm{ow}}$ also increases with molecular weight for the studied contaminants it is an intractable matter to disentangle their relative importance. Aqueous solubility and H-bond $\delta$ were both strongly negatively correlated with rejection, respective $r$ values being -0.852 and -0.828 (Table 3 ). These two properties were negatively correlated with molecular weight and $\log \mathrm{K}_{\mathrm{ow}}$, as shown by $\mathrm{r}$ values from -0.669 to -0.984 (Table 3 ). One again, this illustrates the interlinked nature of the chemical properties, as micropollutants which were best removed by the membrane tended to be among the largest and most hydrophobic compounds and therefore also had low aqueous solubility and low propensity for hydrogen bonding. Boiling point, theoretical vapour pressure values and Henry's Law constants were not well correlated with rejection (Table $3 ; \mathrm{r}=0.566,0.065$ and 0.179 , respectively). Also note that vapour pressure was not strongly correlated with any of the molecular properties related to molecular size (i.e. molecular weight, molecular volume, kinetic diameter), $\mathrm{r} \leq 0.597$ for all. As expected, vapour pressure values were strongly correlated with Henry's Law constants $(r=0.918$; Table 3). Overall, this indicates that physicochemical separation processes, as evidenced by the correlations involving properties associated with molecular weight, hydrophobicity and 
aqueous solubility, rather than vapour pressure, actually drives removal of aromatic contaminants by the investigated pervaporation tube. As mentioned above, the three conceptual steps in the pervaporation process are dissolution, diffusion and evaporation, although there is uncertainty regarding exactly in which location of the membrane these occur. Overall, the calculated correlations suggest that molecular sieving, hydrophobicity and hydrogen bonding are the most influential mechanisms determining the rejection of organics by this type of membrane.

\section{Conclusions}

Rejection of organic contaminants by the tubular, hydrophilic pervaporative membrane in this study increased with the size of aromatic micro-pollutant. Solubility, hydrophobicity and hydrogen-bonding also played a role. Molecular weight and $\log \mathrm{K}_{\mathrm{ow}}$ had the strongest positive relationships with rejection, as demonstrated by respective correlation coefficients of $\mathrm{r}=$ 0.898 and 0.824 . Rejection was also strongly negatively correlated with aqueous solubility and H-bond $\delta$. However, properties which relate to vapour phase concentrations of the micropollutants were not well correlated with rejection. Thus, physicochemical separation processes, rather than vapour pressure, drives removal of aromatic contaminants by the investigated pervaporation tube. Based on these experiments, the application of hydrophilic pervaporative membranes for treating organics-contaminated waters might pose some risks to the long-term quality of the surrounding soil and plant life, depending on the particular organic compounds present in the water; this research provides evidence of relationships that can be used as a basis for assessing whether such organics are likely to permeate into the soils or not. 


\section{Acknowledgements}

We gratefully acknowledge the funding for this work provided by the Research Partnership to Secure Energy for America (RPSEA) under Project Number 09123-11. The authors also acknowledge the in-kind support and guidance of Mark Tonkin of DTI-r Ltdm, Audrey Cally, Jean-Maurice Griffon and Christophe Chervin of DuPont, and Dr Jonathan Brant of the University of Wyoming. The PhD studentship of first author was funded by the Petroleum Technology Development Fund (PTDF) of Nigeria.

\section{References}

1. Neff JM, Johnsen S, Frost TK, Røe Utvik TI, Durell GS. Oil well produced water discharges to the North Sea. Part II: Comparison of deployed mussels (Mytilus edulis) and the DREAM model to predict ecological risk. Mar Environ Res. 2006;62:224-46.

2. Zhao K, Xiu G, Xu L, Zhang D, Zhang X, Deshusses MA. Biological treatment of mixtures of toluene and n-hexane vapours in a hollow fibre membrane bioreactor. Environ. Technol. 2011;32:617-23.

3. Wang X-Q, Lu B-H, Zhou X-X, Li W. Evaluation of o-xylene and other volatile organic compounds removal using a xylene-acclimated biotrickling filter. Environ. Technol. 2013;34:2691-9.

4. Shahriari H, Fernandes L, Tezel FH. Investigation of organic, inorganic and synthetic adsorbents for the pretreatment of landfill leachate. Environ. Technol.. 2008;29:543-52.

5. Wijmans JG, Baker RW. The solution-diffusion model: a review. J Membrane Sci. 1995;107:1-21.

6. Baker R. Membrane Technology and Applications. Second ed. Chichester, UK: John Wiley \& Sons Ltd; 2004.

7. Sule M, Jiang J, Templeton M, Huth E, Brant J, Bond T. Salt rejection and water flux through a tubular pervaporative polymer membrane designed for irrigation applications.

Environ Technol. 2013;34:1329-39.

8. Chemspider. Chemical data base search 2015 [cited 201522 October 2015]. Available from: http://www.chemspider.com/Search.aspx.

9. Yaws CL, Narasimhan P, K. , Gabbula C. Yaws' Handbook of Antoine Coefficients for Vapor Pressure (2nd Electronic Edition): Knovel. Online version available at: http://app.knovel.com/hotlink/toc/id:kpYHACVPEH/yaws-handbook-antoine/yawshandbook-antoine; 2009 [rom: URL|.

10. Hansen CM. Hansen Solubility Parameters. A User's Handbook. Second Edition. Boca Raton, FL, USA: CRC Press; 2007.

11. Shao P, Huang RYM. Polymeric membrane pervaporation. J. Membrane Sci. 2007;287:162-79.

12. Park JK, Sakti JP, Hoopes JA. Transport of organic compounds in thermoplastic geomembranes .1. Mathematical model. J. Environ. Eng.(ASCE). 1996;122:800-6.

13. Islam MZ, Rowe RK. Permeation of BTEX through unaged and aged HDPE geomembranes. J. Geotech. Geoenviron. Eng. 2009;135:1130-40. 
14. Quiñones-Bolaños E, Zhou H, Soundararajan R, Otten L. Water and solute transport in pervaporation hydrophilic membranes to reclaim contaminated water for micro-irrigation. J. Membrane Sci. 2005;252:19-28.

15. Shaw DG, Maczynski A, Goral M, Wisniewska-Goclowska B, Skrzecz A, Owczarek I, Blazej K, Haulait-Pirson M-C, Hefter GT, Huyskens PL, Kapuku F, Maczynska Z, Szafranski A. IUPAC-NIST Solubility Data Series. 81. Hydrocarbons with Water and Seawater-Revised and Updated. Part 9. C10 Hydrocarbons with Water. J. Phys. Chem. Ref. Data. 2006;35:93-151.

16. Shaw DG, Maczynski A, Goral M, Wisniewska-Goclowska B, Skrzecz A, Owczarek I, Blazej K, Haulait-Pirson M-C, Hefter GT, Kapuku F, Maczynska Z, Szafranski A. IUPACNIST Solubility Data Series. 81. Hydrocarbons with Water and Seawater-Revised and Updated. Part 11. C13-C36 Hydrocarbons with Water. J. Phys. Chem. Ref. Data. 2006;35:687-784.

17. ISO/IEC. 17025: General requirements for the competence of testing and calibration laboratories. The International Organization for Standardization (ISO) and the International Electrotechnical Commission (IEC) Genva, Switzerland: ISO/IEC; 2005.

18. Atkins PW. Physical Chemistry. Fifth ed. Oxford, Melbourne, Tokyo: Oxford University Press; 1994.

19. Bartell FE, Thomas TL, Fu Y. Thermodynamics of adsorption from solutions. IV. Temperature dependence of adsorption. J. Phys. Chem. 1951;55:1456-62.

20. Wijmans JG, Athayde AL, Daniels R, Ly JH, Kamaruddin HD, Pinnau I. The role of boundary layers in the removal of volatile organic compounds from water by pervaporation. $\mathrm{J}$ Membrane Sci. 1996;109:135-46.

21. Böddeker KW, Bengtson G, Bode E. Pervaporation of low volatility aromatics from water. J. Membrane Sci. 1990;53:143-58.

22. Berens AR. Prediction of organic chemical permeation through PVC pipe. Journal AWWA. 1985;77:57-64.

23. Park JK, Bontoux L, Holsen TM, Jenkins D, Selleck RE. Permeation of polybutylene pipe and gasket material by organic chemicals. Journal AWWA. 1991;83:71-8.

24. Sangam HP, Rowe RK. Migration of dilute aqueous organic pollutants through HDPE geomembranes. Geotext. Geomembranes. 2001;19:329-57.

25. Joo JC, Kim JY, Nam K. Mass transfer of organic compounds in dilute aqueous solutions into high density polyethylene geomembranes. J. Environ. Eng. (ASCE). 2004;130:175-83.

26. Rowe RK, Mukunoki T, Sangam HP. Benzene, toluene, ethylbenzene, m\&p-xylene, o-xylene diffusion and sorption for a geosynthetic clay liner at two temperatures. J. Geotech. Geoenviron. Eng. 2005;131:1211-21.

27. Semenova SI, Ohya H, Soontarapa K. Hydrophilic membranes for pervaporation: An analytical review. Desalination. 1997;110:251-86. 
1

2

3

4

5

6

7

8

9

10

11

12

13

14

15

16

17

18

19

20

21

22

23

24

25

26

27

28

29

30

31

32

33

34

35

36

37

38

39

40

41

42

43

44

45

46

47

48

49

50

51

52

53

54

55

56

57

58

59

60

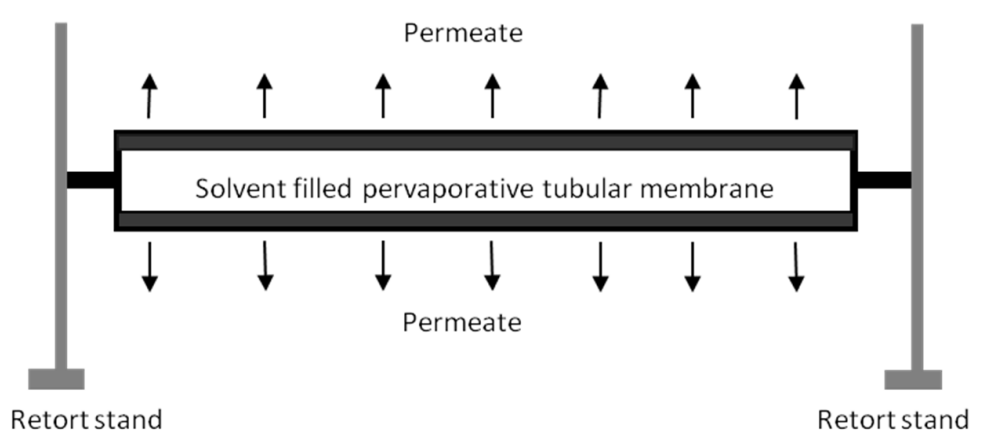

Figure 1: Illustration of the filled tubular membrane clamped and suspended in air. 
a.
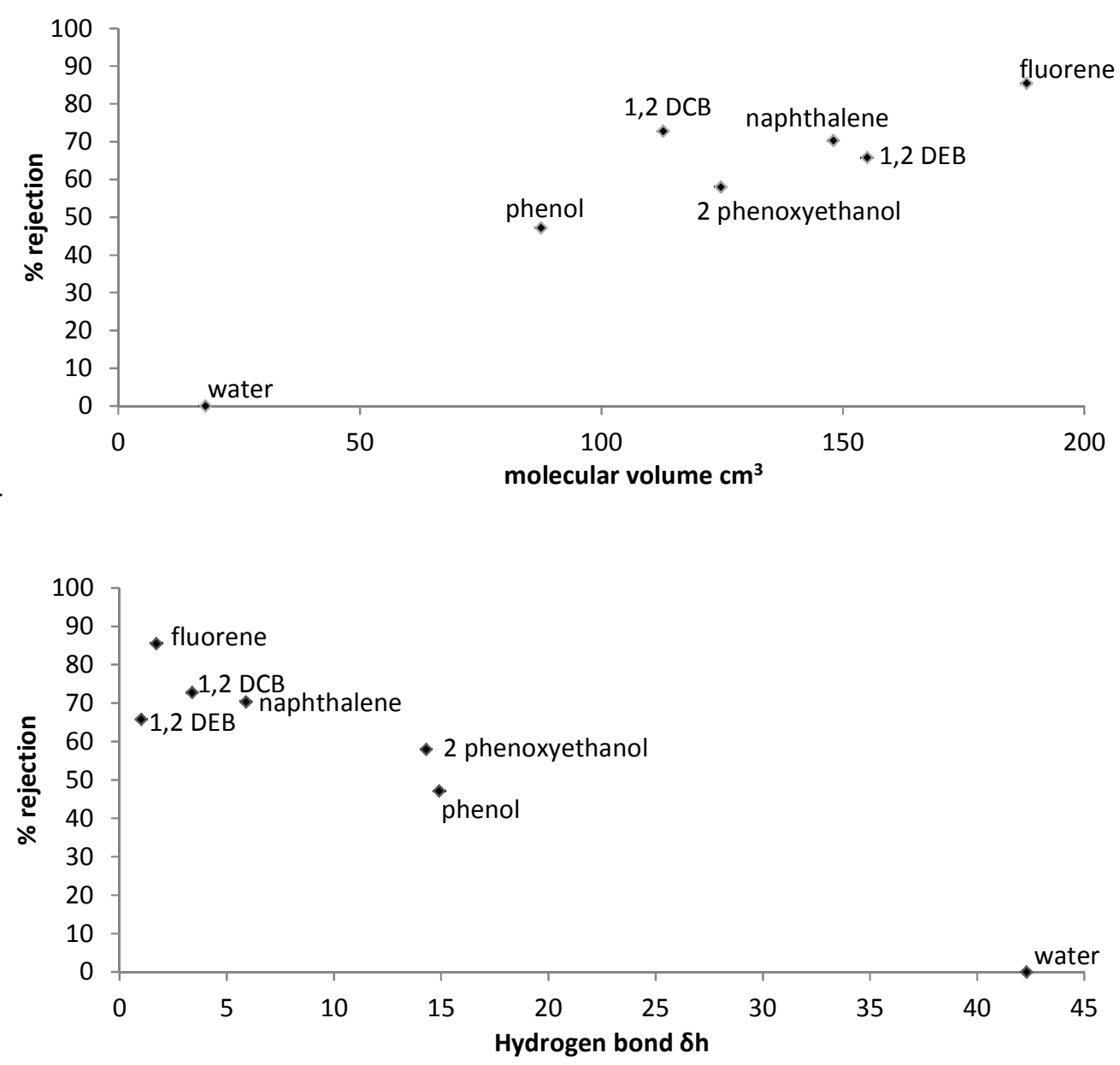

b.

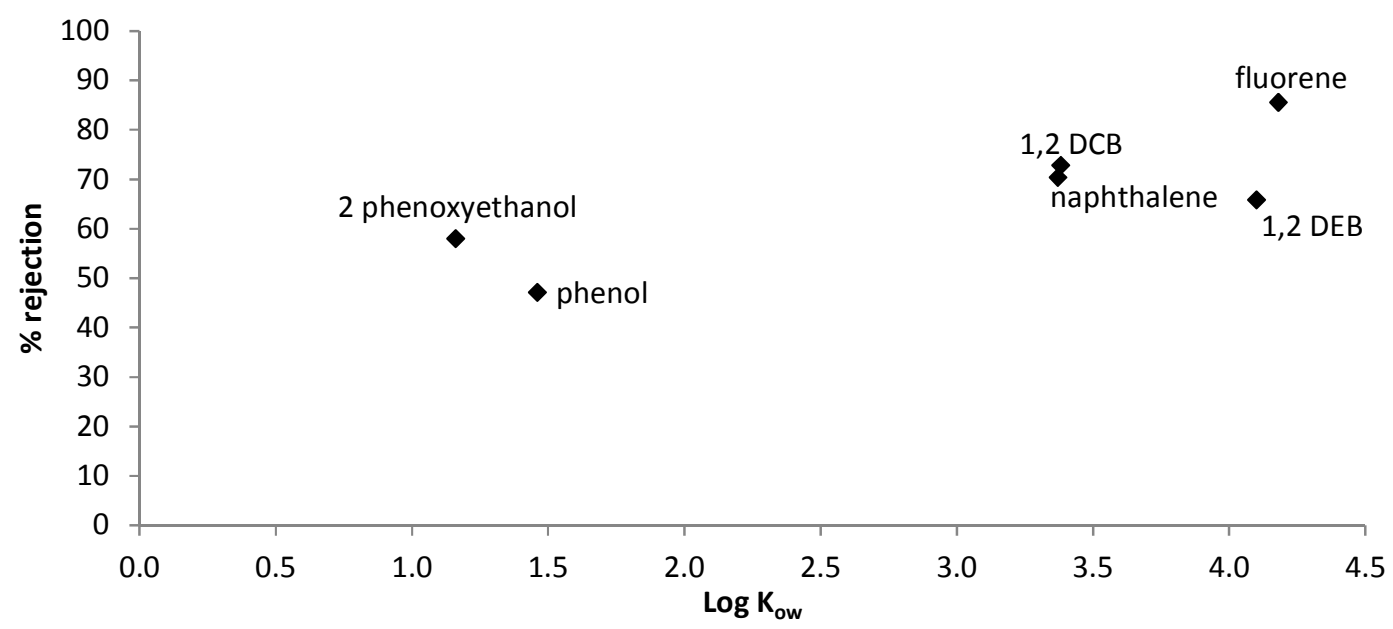

c.

Figure 2: Percentage rejection versus (a) molecular volume (b) hydrogen bonding parameter values, and (c) $\log \mathrm{K}_{\mathrm{ow}}$ values for fluorene, naphthalene, phenol, 1,2-diethylbenzene, 2phenoxyethanol, and 1,2-dichlorobenzene. 
Table 1: Structures and properties of model contaminants $[8,9,10]$

\begin{tabular}{|c|c|c|c|c|c|c|c|c|c|c|c|}
\hline Compound & Structure & $\begin{array}{c}\text { Molecular } \\
\text { weight } \\
\mathrm{g} \cdot \mathrm{mol}^{-1}\end{array}$ & $\begin{array}{l}\text { Density } \\
\mathrm{g} \cdot \mathrm{cm}^{-3}\end{array}$ & $\begin{array}{c}\begin{array}{c}\text { Molar } \\
\text { volume }\end{array} \\
\mathrm{cm}^{3} \\
\mathrm{~mol}^{-1} \\
\end{array}$ & $\begin{array}{l}\text { Aqueous } \\
\text { solubility } \\
\mathrm{mg} \cdot \mathrm{L}^{-1}\end{array}$ & $\log K_{\text {ow }}$ & $\begin{array}{c}\text { Boiling } \\
\text { point } \\
{ }^{\circ} \mathrm{C}\end{array}$ & $\begin{array}{l}\text { H-bond } \\
\quad \delta \\
\mathrm{MPa}^{1 / 2}\end{array}$ & $\begin{array}{c}\begin{array}{c}\text { Kinetic } \\
\text { diameter }\end{array} \\
\AA\end{array}$ & $\begin{array}{c}\text { Henry's } \\
\text { Law } \\
\text { constant }^{2} \\
\text { atm- } \\
\mathrm{m}^{3} / \mathrm{mol} \\
\end{array}$ & $\begin{array}{c}\text { Vapour pressure } \\
\text { @ } 25^{\circ} \mathrm{C}^{3} \\
\mathrm{~mm} \mathrm{Hg}\end{array}$ \\
\hline Fluorene & & 166 & 1.2 & 138 & 2 & 4.2 & 295 & 1.7 & & $9.62 \mathrm{E}-05$ & 0.008 \\
\hline Naphthalene & & 128 & 1.1 & 112 & 31 & 3.4 & 218 & 5.9 & 7.2 & 4.40E-04 & 0.077 \\
\hline Phenol & & 94 & 1.1 & 88 & 8000 & 1.5 & 182 & 14.9 & 6.6 & 3.33E-07 & 0.296 \\
\hline $\begin{array}{c}1,2- \\
\text { Diethylbenzene }\end{array}$ & & 134 & 0.9 & 153 & 70 & 4.1 & 183 & 1.0 & 7.8 & 2.61E-03 & 1.200 \\
\hline $\begin{array}{c}2- \\
\text { Phenoxyethanol }\end{array}$ & & 138 & 1.1 & 125 & 3000 & 1.2 & 246 & 14.3 & & $4.72 \mathrm{E}-08$ & 0.011 \\
\hline $\begin{array}{c}1,2- \\
\text { Dichlorobenzene }\end{array}$ & & 147 & 1.3 & 113 & 140 & 3.4 & 181 & 3.4 & 7.3 & $1.92 \mathrm{E}-03$ & 1.480 \\
\hline
\end{tabular}

1 = calculated from molecular weight/density. 2 = experimental value. 3 = calculated from the Antoine equation, see the manuscript text. Correlations involving Antoine coefficients a, b and c are shown in Table 3, but these coefficients have been excluded from Table 1 due to lack of space. 
Table 2: Average permeate flux, percentage rejection versus solubility for fluorene, naphthalene, 1,2 diethylbenzene, 1,2 dichlorobenzene, 2-phenoxyethanol, and phenol

\begin{tabular}{lccccc}
\hline Compound & $\begin{array}{c}\text { Solubility } \\
\text { in water } \\
\mathbf{m g} / \mathbf{L}\end{array}$ & $\begin{array}{c}\text { Feed concn } \\
\mathbf{m g} / \mathbf{L}\end{array}$ & Rejection\% & $\begin{array}{c}\text { Ave permeate } \\
\text { flux } \mathbf{L}\left(\mathbf{m}^{-\mathbf{2}} \cdot \mathbf{h}^{\mathbf{- 1}}\right)\end{array}$ & Std dev \\
\hline Fluorene & 2 & 1.75 & 85.5 & $3.9 \times 10^{-2}$ & $6.8 \times 10^{-4}$ \\
Naphthalene & 31 & 28 & 70.3 & $3.9 \times 10^{-2}$ & $8.4 \times 10^{-4}$ \\
1,2 Diethylbenzene & 70 & 68 & 65.8 & $3.7 \times 10^{-2}$ & $7.1 \times 10^{-4}$ \\
1,2 Dichlorobenzene & 140 & 138 & 72.7 & $3.8 \times 10^{-2}$ & $9.9 \times 10^{-4}$ \\
2-Phenoxyethanol & 3000 & 300 & 57.9 & $3.8 \times 10^{-2}$ & $2.0 \times 10^{-3}$ \\
Phenol & 8000 & 300 & 47.1 & $3.7 \times 10^{-2}$ & $7.6 \times 10^{-4}$ \\
Deionised water & & & & $5.5 \times 10^{-2}$ & $8.5 \times 10^{-4}$ \\
\hline
\end{tabular}


Table 3: Pearson product-moment correlation coefficients between chemical properties and rejection values

\begin{tabular}{|c|c|c|c|c|c|c|c|c|c|c|c|c|c|}
\hline & $\begin{array}{c}\% \\
\text { rejection }\end{array}$ & $\begin{array}{c}\text { Mol } \\
\text { weight }\end{array}$ & Density & $\begin{array}{l}\text { Molar } \\
\text { volume }\end{array}$ & $\begin{array}{l}\text { Aqueous } \\
\text { solubility }\end{array}$ & $\log K_{0 w}$ & $\begin{array}{c}\text { Boiling } \\
\text { point }\end{array}$ & H-bond $\delta$ & $\begin{array}{c}\text { Kinetic } \\
\text { diameter }\end{array}$ & $\begin{array}{c}\text { Henry's } \\
\text { Law } \\
\text { constant }\end{array}$ & $A^{1}$ & $\mathbf{B}^{1}$ & $C^{1}$ \\
\hline Mol. weight & 0.898 & & & & & & & & & & & & \\
\hline Density & 0.431 & 0.402 & & & & & & & & & & & \\
\hline Molar volume & 0.563 & 0.686 & -0.386 & & & & & & & & & & \\
\hline Aqueous sol. & -0.852 & -0.812 & -0.172 & -0.711 & & & & & & & & & \\
\hline $\log K_{\text {ow }}$ & 0.824 & 0.607 & 0.009 & 0.629 & -0.805 & & & & & & & & \\
\hline Boiling point & 0.566 & 0.645 & 0.288 & 0.353 & -0.278 & 0.139 & & & & & & & \\
\hline H-bond $\delta$ & -0.828 & -0.669 & -0.040 & -0.676 & 0.853 & -0.984 & -0.099 & & & & & & \\
\hline $\begin{array}{l}\text { Kinetic } \\
\text { diameter }\end{array}$ & 0.696 & 0.773 & -0.381 & 0.977 & -0.841 & 0.964 & -0.002 & -0.955 & & & & & \\
\hline $\begin{array}{l}\text { Henry's Law } \\
\text { constant }\end{array}$ & 0.179 & 0.169 & -0.308 & 0.489 & -0.494 & 0.561 & -0.584 & -0.650 & 0.895 & & & & \\
\hline Antoine's $\mathbf{A}^{1}$ & -0.369 & -0.052 & -0.061 & -0.065 & 0.547 & -0.678 & 0.463 & 0.665 & -0.658 & -0.622 & & & \\
\hline Antoine's B ${ }^{1}$ & 0.404 & 0.613 & 0.194 & 0.400 & -0.112 & -0.004 & 0.913 & 0.004 & 0.090 & -0.491 & 0.694 & & \\
\hline Antoine's $C^{1}$ & 0.559 & 0.701 & 0.076 & 0.659 & -0.437 & 0.536 & 0.240 & -0.618 & 0.613 & 0.471 & 0.057 & 0.460 & \\
\hline Vap pressure & 0.065 & 0.071 & -0.051 & 0.193 & -0.290 & 0.377 & -0.696 & -0.485 & 0.597 & 0.918 & -0.551 & -0.542 & 0.469 \\
\hline
\end{tabular}

$\mathrm{A}, \mathrm{B}$ and $\mathrm{C}$ are used as abbreviations for Antoine's coefficients A, B and C 